\title{
Chromosomal Localization of Three Human Ras Genes by In Situ Molecular Hybridization
}

\section{N.C. Popescu, S.C. Amsbaugh, J.A. DiPaolo, S.R. Tronick, S.A. Aaronson, and D.C. Swan}

On p. 152 of this article (Somat. Cell Mol. Genet. 11: 149-155) an incorrect photograph was inserted as Fig. 3. The correct Fig. 3 appears here along with its caption.

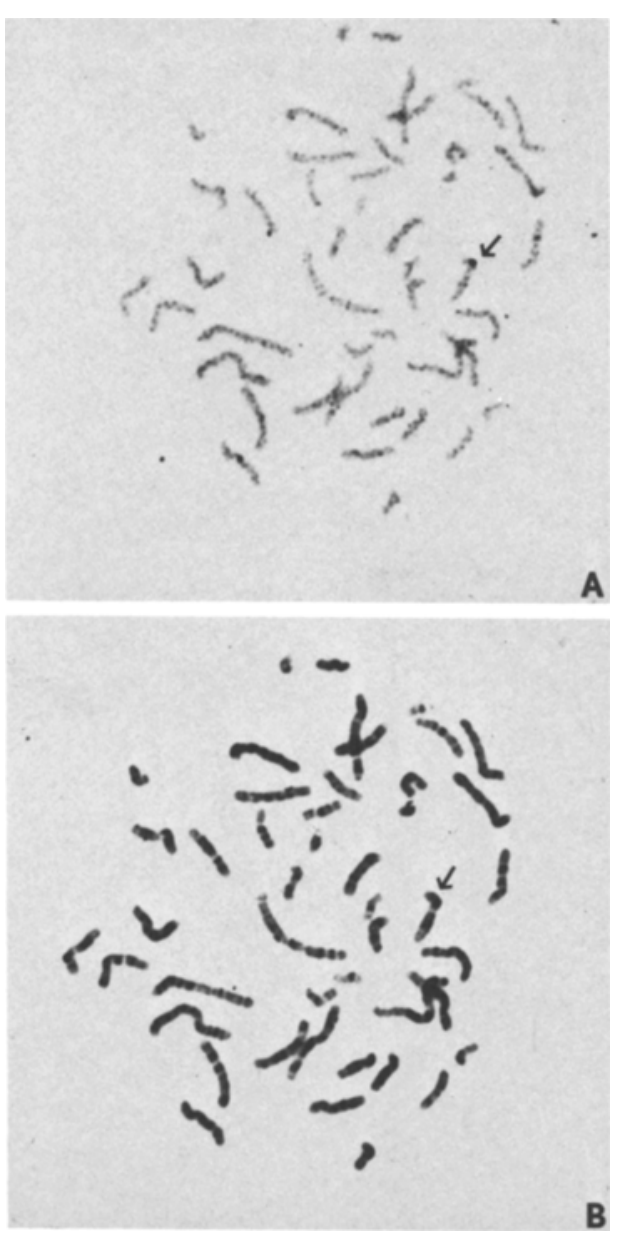

Fig. 3. Sequential staining of human mitotic chromosomes after in situ hybridization to a c-Ki-ras probe: (A) Wright-stained chromosomes with silver grains, and (B) G-bands after treatment with trypsin-EDTA and restained. Arrows indicate grain localized to $12 \mathrm{p} 11.1$. 